Article

\title{
Structure Characteristics Affected by Material Plastic Flow in Twist Channel Angular Pressed Al/Cu Clad Composites
}

\author{
Lenka Kunčická ${ }^{1, *}$ and Zuzana Klečková ${ }^{2}$ \\ 1 Institute of Physics of Materials, ASCR, 61662 Brno, Czech Republic \\ 2 Department of Thermal Engineering, Faculty of Metallurgy and Materials Engineering, VŠB TU Ostrava 17. \\ Listopadu 15, 70833 Ostrava-Poruba, Czech Republic; zuzana.kleckova@vsb.cz \\ * Correspondence: kuncicka@ipm.cz; Tel.: +420-532-290-371
}

Received: 23 August 2020; Accepted: 16 September 2020; Published: 18 September 2020

\begin{abstract}
The study focuses on structure analyses, texture analyses in particular, of an $\mathrm{Al} / \mathrm{Cu}$ clad composite manufactured by single and double pass of the twist channel angular pressing (TCAP) method. Microscopic analyses were supplemented with numerical predictions focused on the effective imposed strain and material plastic flow, and microhardness measurements. Both the TCAP passes imparted characteristic texture orientations to the reinforcing $\mathrm{Cu}$ wires, however, the individual preferential grains' orientations throughout the composite differed and depended on the location of the particular wire within the $\mathrm{Al}$ sheath during extrusion, i.e., on the dominant acting strain path. The second TCAP pass resulted in texture homogenization; all the $\mathrm{Cu}$ wires finally exhibited dominant A fiber shear texture. This finding was in accordance with the homogenization of the imposed strain predicted after the second TCAP pass. The results also revealed that both the component metals exhibited significant deformation strengthening (which also caused bending of the ends of the $\mathrm{Cu}$ wires within the $\mathrm{Al}$ sheath after extrusion). The average microhardness of the $\mathrm{Cu}$ wires after the second pass reached up to $128 \mathrm{HV}$, while for the $\mathrm{Al}$ sheath the value was $86 \mathrm{HV}$.
\end{abstract}

Keywords: clad composite; rotary swaging; finite element analysis; effective strain; residual stress

\section{Introduction}

Composite materials can generally be characterized as materials consisting of two or more phases or components featuring different physical and chemical properties, separated by mutual interfaces [1,2]. The existence of the interfaces differentiates composites from alloys manufactured conventionally, e.g., by melting and subsequent casting. Combining different metals (featuring advantageous formability, strength, and thermal and electrical conductivities), possibly with other materials, such as ceramics (featuring favorable hardness, strength, tolerance to high temperatures, and low thermal expansion), brings about the possibility to produce composite materials with higher utility properties than those of numerous single-phase materials and alloys [3,4].

Quite a wide spectrum of composites has been presented so far and their characterization can be performed according to various criteria. Generally, composites consist of a matrix (i.e., first phase), and (several) other phase(s), typically added to enhance the mechanical properties of the final product (i.e., reinforcing phase(s)) [5]. Therefore, composites are usually characterized according to the type of the reinforcing phase. The first type is composites with continuous reinforcing elements, typically long fibers, i.e., continuous composites, whereas the second type is composites with discontinuous reinforcing elements, typically particles, whiskers, short fibers, etc., i.e., discontinuous composites. When compared to the first type, the second type is advantageous due to its easier and cheaper production and variability 
of the final shape of the product achievable during possible secondary treatment (forging, rolling, extrusion, severe plastic deformation (SPD) processing, etc.) [6].

Regardless of the type of composite, the grain size and distribution of the reinforcing phase within the composite have a major influence on the effectivity of enhancement of the mechanical properties. Similar to conventional materials, among the aims of the production of composite materials is to acquire homogeneous fine-grained structures with favorable distributions of the reinforcing elements within the matrices. However, simultaneous achievement of complete consolidation (high quality bonding of the phases) and an ultra-fine-grained (UFG) structure is a challenge when performed via conventional methods, such as hot isostatic pressing (HIP) or extrusion of powder-based materials, and forging of presintered semiproducts [7].

Among the promising methods for the production of UFG composites is powder metallurgy, which can advantageously be used to fabricate microcomposites and nanocomposites when using nanopowders (the size of the individual powder particles is up to hundreds of nanometers). This production method is applicable especially for tiny components for the electrotechnics $[8,9]$. The main advantage of such composites is negligible final porosity and high quality of bonding of the individual powder particles. Among the positive aspects of using nanopowders is also the possibility to apply lower pressures and temperatures during their consolidation/sintering [10], which enables the application of more or less conventional forming methods for the production of such materials. However, the works documenting achievement of the required structure refinement or desired redistribution of the reinforcing elements by conventional forming technologies are scarce (e.g., [11-13]). Nevertheless, compact composites with negligible porosity and a very fine structure can be fabricated via methods of intensive plastic deformation enabling significant structure refinement (formation of UFG structure) without introducing substantial changes in shapes of the processed billets. Intensive shear deformation imparted by the combination of high pressure and rotary movement processed at room/elevated temperatures also supports mutual bonding of the used materials [14-17]. The SPD technologies mostly used to prepare composite materials are the equal channel angular pressing (ECAP) [18-20] and ECAP-based methods [21,22], high pressure torsion (HPT) [23], and accumulative roll bonding (ARB) [24]. ECAP and HPT are advantageous for the consolidation of powders, as well as for their subsequent processing to the final shapes, whereas ARB is especially favorable for enhancing structure refinement of preconsolidated materials [25], or for the preparation of clad composites [26]; the latter has been successfully performed also via the repeated folding (RF) process, the fundamentals of which are similar to ARB [27].

Despite the fact that virtually all the SPD methods are applicable for the preparation of composites, the (sub)structure development is different for multi-phase materials, and single-phase ones. For single-phase materials deformed via methods such as ECAP, substructure formation involves increasing dislocation density and development of cell blocks with large misorientations resulting in the formation of dislocation cells the size of which typically decreases with increasing imposed strain. With continuing deformation, such a substructure gradually transforms into a homogeneous structure featuring fine grains with a high portion (up to $85 \%$ ) of high angle grain boundaries [28]. The minimum achievable grain size for single-phase materials deformed by SPD methods is primarily controlled by the imposed strain, its character (single pass, cyclic, etc.), and processing temperature. On the other hand, the process of (sub)structure formation within multi-phase materials, i.e., composites, deformed via SPD methods is different. Generally, the decrease in the grain size is not directly proportional to the imposed strain; decreasing thickness of the reinforcing component supports a decrease in the grain size within this component during processing. However, the application of critical deformation (i.e., imposed strain, the value of which depends on the material) leads to the formation of amorphous structures and saturated solid solutions, regardless of the used technology [29-32]. Due to the interactions of the individual phases during intensive plastic processing of composites, the achievable grain size for them is generally smaller than for the original single-phase materials; SPD methods are applicable for the preparation of nanocomposites with the average grain sizes of 
$10 \mathrm{~nm}$ [33]. Therefore, the intensive plastic deformation is promising for the preparation of innovative multi-phase composites with enhanced properties.

A specific type of composite is clad composites (sometimes characterized as layered or hybrid materials) consisting of two or more different metals bond at mutual interfaces. These materials are gaining increasing interest in various industrial branches and have been subjects to numerous studies reporting the application of forming technologies for their preparation, e.g., $\mathrm{Al} / \mathrm{steel} / \mathrm{Al}, \mathrm{Ti} / \mathrm{Cu}, \mathrm{Ti} / \mathrm{Al}$, and $\mathrm{Mg} /$ stainless steel were prepared using conventional rolling [34-36]. Nevertheless, rolling is usually combined with other processing technologies, as documented, e.g., by the study reporting the application of explosive bonding and subsequent rolling for the preparation of a Ti/steel clad composite, combining the excellent strength of steel and corrosion resistance of Ti, for the petrochemical industry [37]. Given by the positive effects of the different rotation rates of the rolls on the imposed shear strain, asymmetrical rolling was used to prepare clad composites combining $\mathrm{Al}$ and $\mathrm{Cu}[38,39]$.

The combination of $\mathrm{Al}$ and $\mathrm{Cu}$ is specifically favorable since both the metallic components exhibit excellent electric and heat conductivities. Replacing a portion of $\mathrm{Cu}$ by $\mathrm{Al}$ results in a material featuring lighter weight and reduced cost when compared to $\mathrm{Cu}$. Optimized processing of the composites provides advantageous materials applicable, e.g., in the aerospace and automotive $[40,41]$, or electrotechnics [42]. Given by the combination of light weight and favorable mechanical properties, $\mathrm{Al} / \mathrm{Cu}$ composites are believed to possibly supplement/replace steel in particular applications in vehicles and aircrafts [41]. The studies documented favorable durability of the $\mathrm{Al} / \mathrm{Cu}$ clad composites during dynamic loading (strain rates up to $100 \mathrm{~s}^{-1}$ ), which can primarily be attributed to the development of deformation induced twins. The intensive shear strain does not only support grain refinement, but also introduces friction at mutual interfaces (given by different plastic flows of the component metals), which consequently generates heat supporting mutual bonding of the metals via atomic diffusion. Nevertheless, increasing temperature can also result in the formation of interlayers (intermetallics), which can develop within both, the continuous and discontinuous composites.

Since the conventional forming methods and heat treatments feature certain limitations, unconventional forming, i.e., via the SPD methods, has become favorable also for the preparation of clad composites. SPD is beneficial especially from the viewpoint of introducing homogeneous distribution of secondary particles, as well as grain refinement and possibly UFG structures within the composite metals. Moreover, the shear strain supports corrupting of possible oxide layers at the surfaces of the component metals and increases diffusion via introducing lattice defects [43,44]. Numerous studies have documented substantial enhancement of the final properties of clad composites when prepared using SPD $[16,17,45-47]$. Probably the most promising is the HPT method, which successfully suppresses the development of cracks via applying very high pressures. It also imposes very high strains, which supports redistribution of secondary particles. For the conventional ECAP technology, the strain imposed during a single pass can be increased via modifications of the dies, or by implementing back pressure.

The twist channel angular pressing (TCAP) method combines twist and bend deformation zones within a single equal channel, which enables to impart a substantial shear strain during a single pass $[48,49]$. TCAP has been successfully proven to impart homogeneous UFG structures, and the effectivity of single pass TCAP has been documented to be higher than double pass ECAP [22,50,51].

Since TCAP has only been used for single-phase materials so far, this study focuses on the characterization of the grains' orientations and plastic flow within an $\mathrm{Al} / \mathrm{Cu}$ clad composite processed via single and double pass TCAP. Experimental texture analyses are supplemented with numerical simulations predicting the effective imposed strain values and distribution throughout the extruded composites, as well as documenting the behavior of the billet during processing, especially the behavior of the reinforcing $\mathrm{Cu}$ wires within the $\mathrm{Al}$ sheath. Last but not least, mapping of microhardness throughout the extruded billets' cross-sections was performed. 


\section{Materials and Methods}

The aim of the presented work was to perform detailed characterization of the influences of the applied TCAP process on the behavior of grains within an $\mathrm{Al} / \mathrm{Cu}$ clad composite reinforced with $\mathrm{Cu}$ wires. The study primarily involves the experimental double-pass extrusion, and is supplemented with the numerical prediction of the materials' behaviors. Schematics of the TCAP process acquired from the numerical simulation can be seen in Figure 1. The clad composite consisted of an Al sheath and five reinforcing $\mathrm{Cu}$ wires. Both the experimental and numerically simulated billets were processed via a single pass TCAP, and subsequently via the second pass, deformation route $A$ for which was selected (i.e., the billet was not rotated between the individual passes-details of the selected deformation route and strain paths can be found in $[52,53])$.

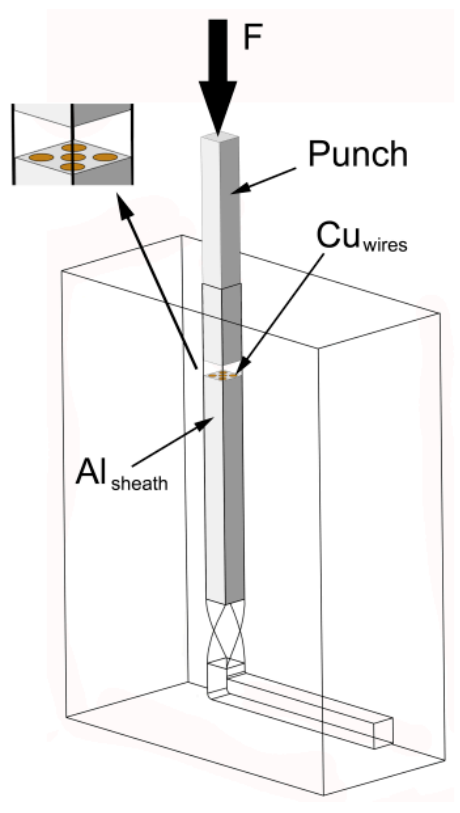

(a)

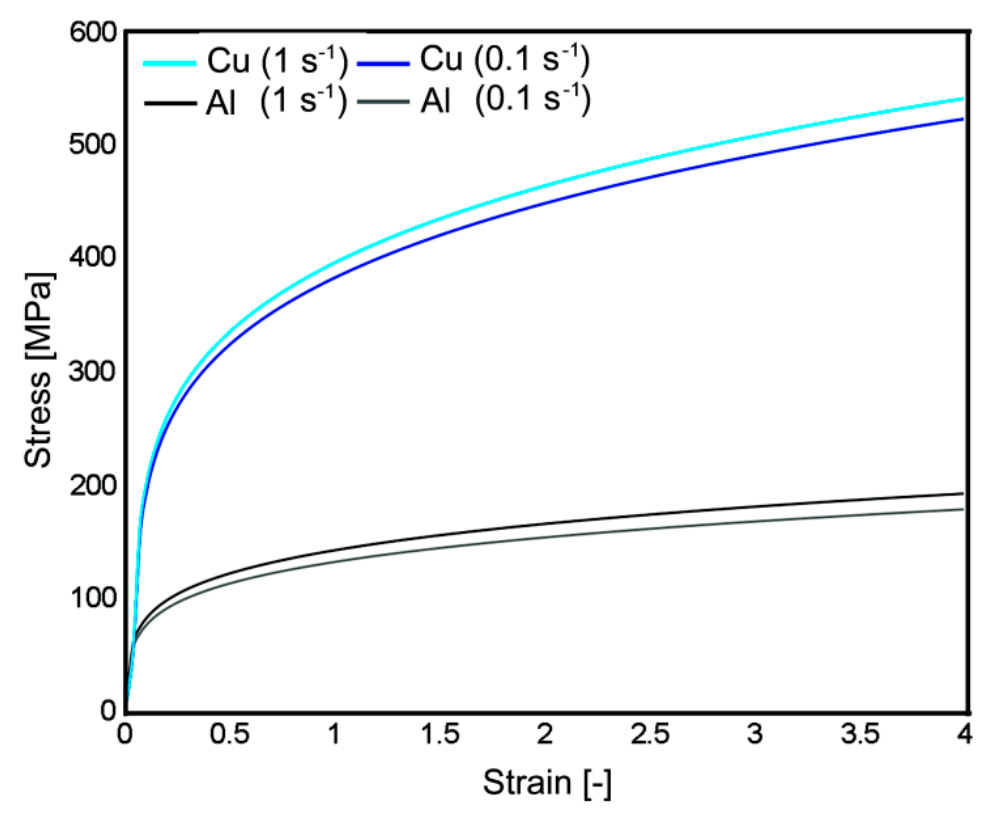

(b)

Figure 1. Schematic depiction of twist channel angular pressing (TCAP) processing of the Al/Cu clad composite (a) and experimental stress-strain data used for numerical simulations (b).

The first part of the study was focused on the practical realization of the TCAP process. The selected component metals were commercially pure (CP) Cu (99.97\%) (Ferona, a.s., Prague, Czech Republic) with the composition of (in wt \%): $0.0074 \mathrm{Ni}, 0.0058 \mathrm{Sn}, 0.0031 \mathrm{Fe}, 0.0030 \mathrm{Zn}, 0.0023 \mathrm{Si}$, and bal. Cu; and $\mathrm{CP} \mathrm{Al}(99.97 \%$ ) with the chemical composition of (in wt $\%): 0.125 \mathrm{Fe}, 0.020 \mathrm{Cu}, 0.020 \mathrm{Zn}, 0.015 \mathrm{Mg}$, $0.015 \mathrm{Mn}, 0.015 \mathrm{Ti}, 0.10 \mathrm{Si}$, and bal. Al. Before preparing the composite billet, all the components were annealed at $500{ }^{\circ} \mathrm{C}$ for $30 \mathrm{~min}$ in an electric furnace. The dimensions of the initial composite billets were $12 \mathrm{~mm} \times 12 \mathrm{~mm}$ (square cross-section) $\times 130 \mathrm{~mm}$ (length). The processing was carried out at room temperature using a hydraulic press, $\mathrm{MoS}_{2}$ (Ferona, a.s., Prague, Czech Republic) was applied as the lubricant. The extrusion rate was $5 \mathrm{~mm} \mathrm{~s}^{-1}$.

The texture analyses of the clad composites processed via the single and double TCAP pass were performed via the SEM-EBSD method (scanning electron microscopy-electron backscatter diffraction). The samples for the analyses were prepared by manual grinding on $\mathrm{SiC}$ papers and subsequent manual/electrolytic polishing by a specific procedure developed by Dr. Michal Jambor, Institute of Physics of Materials, CAS. SEM-EBSD analyses were done using a Tescan Lyra 3 FIB/SEM microscope equipped with a NordlysNano EBSD detector (Oxford Instruments, Abingdon-on-Thames, Great Britain). EBSD scanning was carried out with the accelerating voltage of $20 \mathrm{kV}$ and scan steps of $50 \mathrm{~nm}$. The structure analyses and texture evaluations were performed using AZtecCrystal 1.1 
software, and ATEX software [54]. The mechanical properties of both the extruded composites were investigated by microhardness measurements on cross-sectional cuts from the billets (perpendicular to extrusion axis) using a Zwick/Roell testing machine. The indents spacing was $1 \mathrm{~mm}$ and the applied parameters per indent were: load of $200 \mathrm{~g}$ and loading time of $10 \mathrm{~s}$. The maps were assembled by the own script programmed by Adam Weiser, Institute of Physics of Materials, CAS.

The experimental study was supplemented with numerical simulations of the single and double pass extrusions. The behavior of the composite billet during single and double pass was predicted using the Forge NxT commercial software by Transvalor implementing the finite element method (FEM). The geometrical dimensions and mechanical properties in the numerical model corresponded to the real experimental parameters. The friction was determined as the Coulomb friction $(\mu=0.02)$ and the boundary conditions specified in Table 1 were defined on the basis of a previously performed study in which they were experimentally validated [52]. The geometry of the TCAP die used in both the simulation and experiment was defined by the following angles: $\omega=90^{\circ}, \varphi=90^{\circ}, \beta=40^{\circ}$, and $\psi=20^{\circ}$ (twist rotation angle, channel bending angle, twist slope angle, and arc of curvature of channels' intersection angle, respectively - the angles are described in detail, e.g., in [48,49]). The component metals were characterized using an elastic-plastic model defined by the Newton-Raphson convergent algorithm, and the die and extruder were defined as rigid parts. The clad composite billet was meshed with tetrahedral elements $(215,871$ nodes in total), and automatic remeshing was activated since intensive shear deformations were expected to proceed. The room temperature stress-strain data at the strain rates of 0.1 and $1 \mathrm{~s}^{-1}$ (see Figure 2) imported into the database of the computational software was acquired experimentally for both the used composite metals via torsion tests performed using a servo-hydraulic torsion plastometer (SETARAM). Material behavior was finally determined via the Hansel-Spittel equation (Equation (1)),

$$
\sigma_{f}=A e^{m_{1} T} T^{m_{8}} \varepsilon^{m_{2}} e^{m_{4} / \varepsilon}(1+\varepsilon)^{m_{5} T} e^{m_{6} \varepsilon} \dot{\varepsilon}^{m_{3}} \dot{\varepsilon}^{m_{7} T},
$$

where $\varepsilon$ is the equivalent strain, $T$ is the temperature, $\dot{\varepsilon}$ is the equivalent strain rate, and $A, m_{1}, m_{2}$, $m_{3}, m_{4}, m_{5}, m_{6}, m_{7}, m_{8}$, and $m_{9}$ are regression coefficients. The values of the coefficients for $C u$ were $411.19 \mathrm{MPa},-0.00121,0.21554,0.01472$, and -0.00935 , respectively, and $m_{5} \div m_{8}$ was 0 . The values of the coefficients for $\mathrm{Al}$ were $151.323 \mathrm{MPa},-0.00253,0.21142,0.03177$, and -0.00654 , respectively, and $m_{5}$ $\div m_{8}$ was 0 .

Table 1. Defined boundary conditions for component metals.

\begin{tabular}{cccc}
\hline Property & Unit & Al & $\mathbf{C u}$ \\
\hline Temperature & ${ }^{\circ} \mathrm{C}$ & 25 & 25 \\
Young's modulus & $\mathrm{GPa}$ & 72 & 111 \\
Poisson coefficient & - & 0.3 & 0.3 \\
Thermal expansion & $\mathrm{K}^{-1}$ & $24 \times 10^{-5}$ & $1.7 \times 10^{-5}$ \\
Thermal conductivity & $(\mathrm{W} /(\mathrm{m} \cdot \mathrm{K}))$ & 250 & 394 \\
Specific heat & $\left(\mathrm{J} \cdot \mathrm{kg}^{-1} \cdot \mathrm{K}^{-1}\right)$ & 1230 & 398 \\
Emissivity & - & 0.03 & 0.7 \\
Density & $\left(\mathrm{g} \cdot \mathrm{cm}^{-3}\right)$ & 2.80 & 8.96 \\
\hline
\end{tabular}




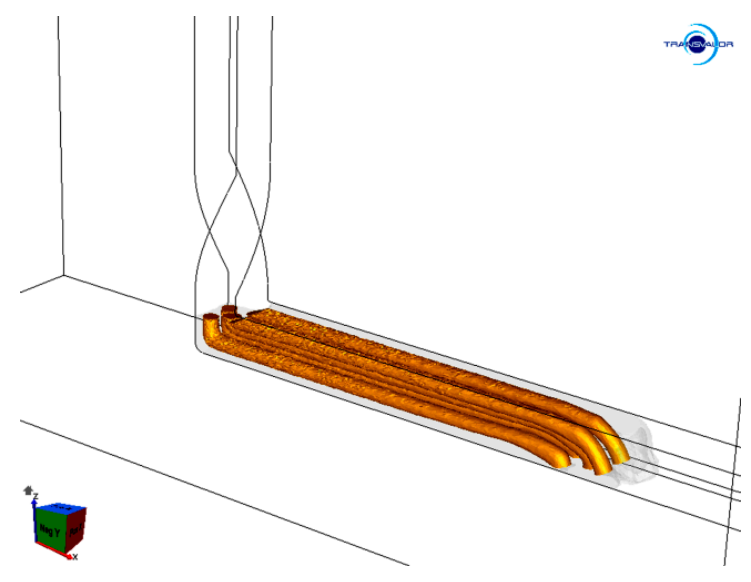

(a)

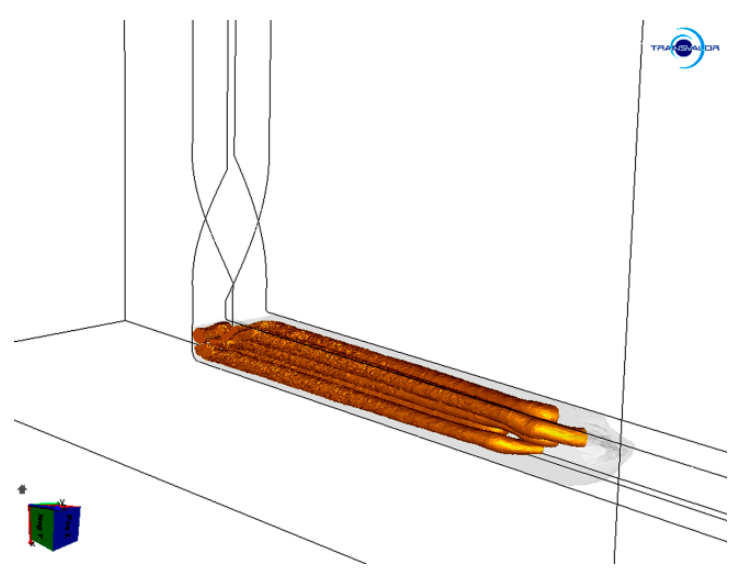

(b)

Figure 2. Deformation behavior of the extruded billet during: single pass (a) and double pass (b).

\section{Results}

\subsection{Numerically Predicted Plastic Flow and Imposed Strain}

The results of the numerical simulation showed that the billets extruded via single and double pass TCAP exhibited differences in their deformation behaviors, as did both the component metals. Figure 2a,b shows images from the simulations, the billets extruded via one and two TCAP passes in which were depicted, respectively. In Figure $2 \mathrm{a}, \mathrm{b}$, the Al sheath was visible as a contour so that the shapes of the $\mathrm{Cu}$ wires could clearly be seen. Both the TCAP passes imparted significant plastic deformation of both the composite components. However, differences between the single and double pass were observed, especially for the $\mathrm{Cu}$ wires.

As can be seen from the prediction, the ends of the $\mathrm{Cu}$ wires were bent downwards to the bottom of the horizontal channel after the single pass (Figure 2a), which originated when passing through the channel bending, i.e., the main deformation zone (MDZ). Additionally, the two upper wires were shifted forward after extrusion. This phenomenon can be attributed to the fact that, in the MDZ, the material plastic flow in the upper cross-sectional region of the composite billet was faster than in its bottom cross-sectional region. Additionally, the shear strain imposed to the composite in the MDZ was more significant along the inner periphery of the channel bending than along its outer periphery [55].

After the simulated double pass, the $\mathrm{Cu}$ wires were bent towards the side of the horizontal channel (Figure 2b). This can primarily be attributed to the selected deformation route ( $A$, see Section 2 and references. [52,53]), which involved no rotation between the passes. By the effect of the presence of the twist deformation zone (TDZ), the locations of the four peripheral $\mathrm{Cu}$ wires changed during the second extrusion, i.e., the billet cross-section rotated by $90^{\circ}$ compared to the cross-section of the billet extruded via a single pass. In other words, the $\mathrm{Cu}$ wire located in the upper left corner of the composite after the first pass shifted to the bottom left corner after the second pass, etc.

The development of the imposed effective strain during a TCAP pass is rather complicated. The TDZ primarily affects the peripheral/corner regions of the extruded billet, by the effect of which the imposed strain did not influence the reinforcing $\mathrm{Cu}$ wires as much as the (periphery of) $\mathrm{Al}$ sheath in this deformation zone. The $\mathrm{Cu}$ wires were not significantly affected by the shear strain during passing through the TDZ, but later on, during passing through the MDZ. As depicted in the cross-sectional cut through the simulated billet extruded via a single pass in Figure 3a, the Al sheath exhibited homogeneous imposed effective strain distribution of rather high values (up to 2.5) when compared to the $\mathrm{Cu}$ wires, the maximum effective strain values in which reached up to 1.5. Moreover, the imposed strain distribution through the wires' cross-sections was not homogeneous after single pass TCAP. Both phenomena were caused by the significantly lower effect of the TDZ on the wires (compared to the Al sheath). 


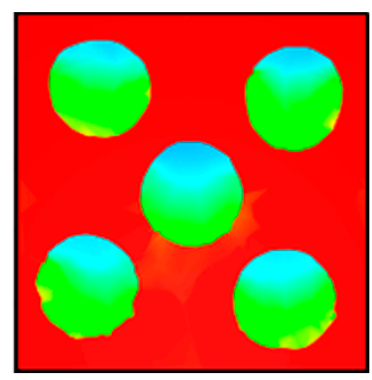

Effective strain [-]

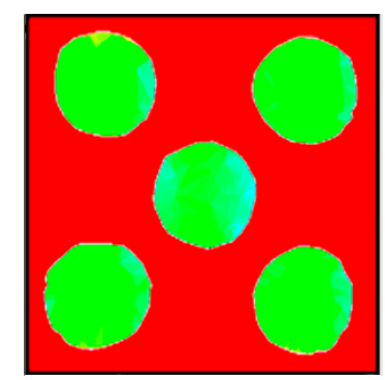

Effective strain [-]

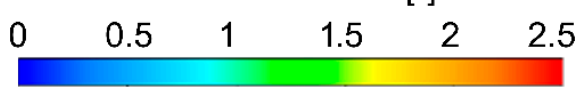

(a)

(b)

Figure 3. Effective strain distribution after: single pass (a) and double pass (b).

The prediction showed that after the double pass, the effect of the TDZ on the imposed strain was more evident than after the single pass for both the composite metals. As can be seen in Figure $3 \mathrm{~b}$ depicting a cross-sectional cut through the billet extruded via double pass TCAP, the Al sheath exhibited the homogeneous distribution of the effective imposed strain (similar to the single pass), however, the maximum imposed strain values almost doubled (up to 5). The $\mathrm{Cu}$ wires exhibited not only an increase in the maximum imposed strain after the second pass, but also substantial homogenization of its distribution (please note the different scales, although the color scheme is maintained for both the Figure $3 a, b$ - decreasing the range of the scale in Figure 3a enables better depiction of the inhomogeneities of the effective imposed strain within the $\mathrm{Cu}$ wires observed after the first TCAP pass).

\subsection{Texture Characteristics of Extruded Composites}

The effects of the TDZ and MDZ on texture developments within the experimentally extruded composite billets were evaluated via pole figures $(\mathrm{PF})$, and via determination of the intensities of dominant ideal shear texture orientations [56-58]. Since the effects of the TCAP process on texture development within the $\mathrm{Al}$ sheath were comparable to its effects on texture development within a $\mathrm{CP}$ Al billet, which were characterized in the previously published study [50], this study primarily focuses on the $\mathrm{Cu}$ wires.

The original preannealed Cu exhibited more or less random texture with a slight tendency to form ideal cube recrystallization texture (not shown here). The texture orientations within the individual wires exhibited differences after the first pass-the individual $\{001\},\{011\}$, and $\{111\}$ PFs for the wires in the upper left, upper right, axial, bottom left, and bottom right positions are depicted in Figure 4a-e, respectively. As can be seen, the highest texture intensity was detected in the axial wire (Figure 4c), which exhibited dominant A fiber ideal shear texture orientation (i.e., \{111\}||shear plane) [56]. Regarding the peripheral wires, the pairs of the wires positioned across the cross-sectional diagonals exhibited tendencies to mirror. The bottom left (Figure $4 \mathrm{~d}$ ) and upper right (Figure $4 \mathrm{~b}$ ) wires primarily formed the $C$ fiber ideal shear texture orientation (although by approximately $10^{\circ}$ shifted), sometimes also denoted as the dominant $\alpha$ fiber defined by the Euler angles $\varphi_{1}, \phi$, and $\varphi_{2}$ of $90^{\circ}, 45^{\circ}$, and $0^{\circ}[57,58]$, and the upper left (Figure 4a) and bottom right (Figure 4e) wires exhibited the tendencies to preferably form the $\mathrm{Ab}$ shear texture orientation (belonging to the A fiber, defined by the Euler angles $\varphi_{1}, \phi$, and $\varphi_{2}$ of $180^{\circ}, 35.26^{\circ}$, and $45^{\circ}$, respectively). However, the Ab ideal orientation was shifted towards the $\mathrm{Bb}$ ideal orientation (Euler angles $\varphi_{1}, \phi$, and $\varphi_{2}$ of $180^{\circ}, 54.74^{\circ}$, and $45^{\circ}$ ), especially within the upper left wire (Figure 4a). 

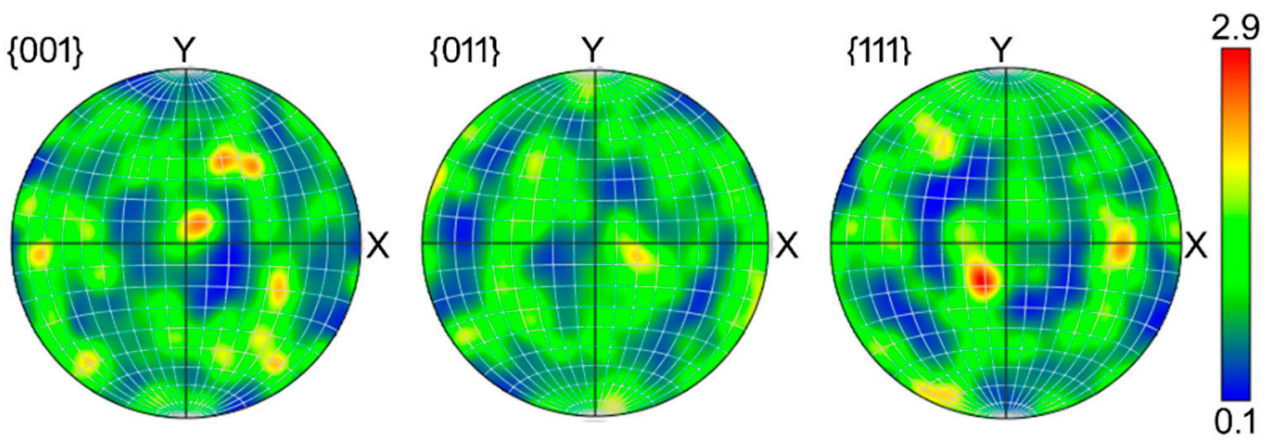

(a)
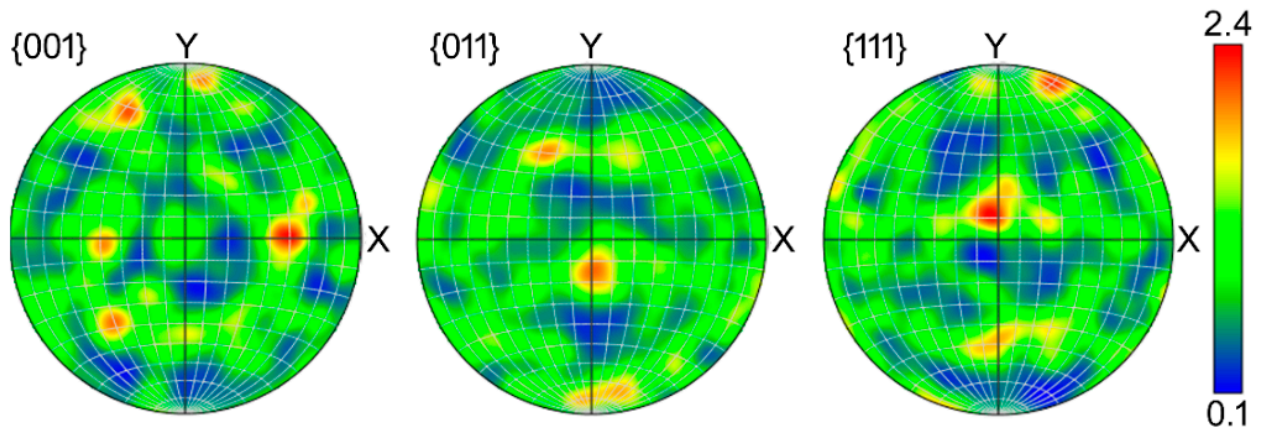

(b)
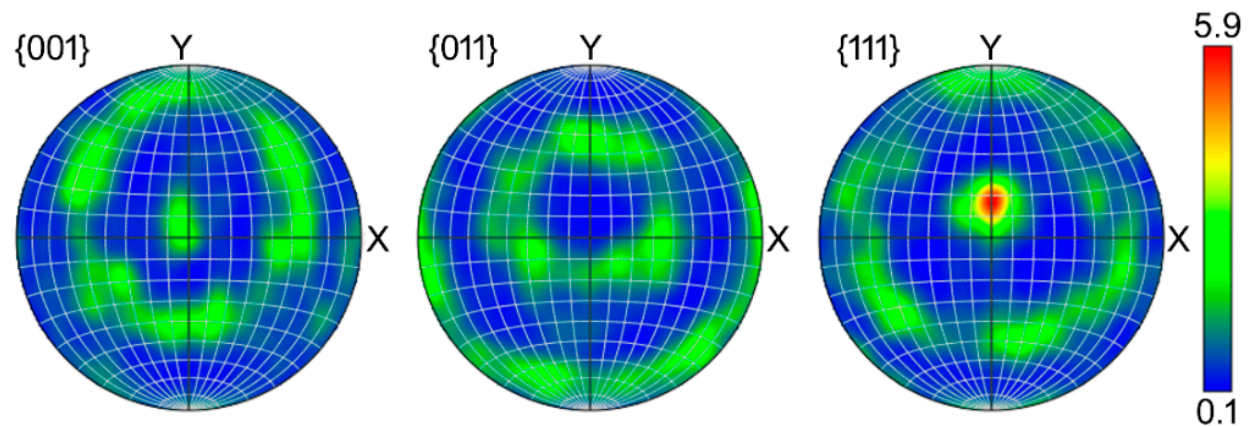

(c)
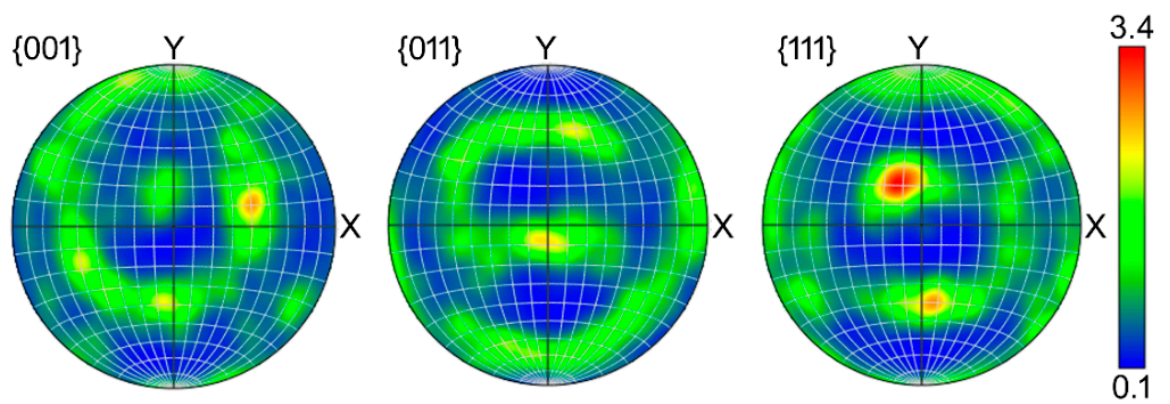

(d)

Figure 4. Cont. 

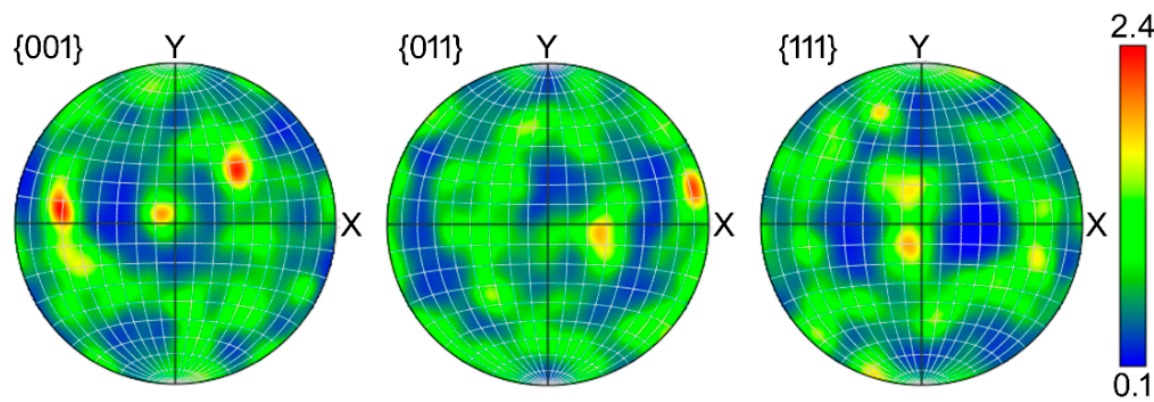

(e)

Figure 4. Pole figures for individual wires within composite billet extruded via single pass TCAP: upper left (a); upper right (b); axial (c); bottom left (d); and bottom right (e).

After the experimental double pass TCAP, homogenization of the textures within the wires occurred. Figure 5a-e depicts the distributions of the main ideal texture orientations within the individual wires after the second TCAP pass. All the wires exhibited dominant texture orientations belonging to the A fiber, however, the suborientations varied slightly (orientations belonging to the $\mathrm{B}$ and $\mathrm{C}$ fibers are not depicted since their volume fractions were neglectable). A1 and A2 ideal texture components (Euler angles $\varphi_{1}, \phi$, and $\varphi_{2}$ of $35.26^{\circ}, 45^{\circ}$, and $0^{\circ}$; and $144.74^{\circ}, 45^{\circ}$, and $0^{\circ}$, respectively) were dominant in all the wires after the second TCAP pass, except the upper right wire (Figure $5 b$ ), $\mathrm{Ab}$ ideal orientation for which was dominant. This wire was located in the bottom right position after the first pass (after which the texture already exhibited the tendency to form the Ab ideal orientation, see Figure 4e).

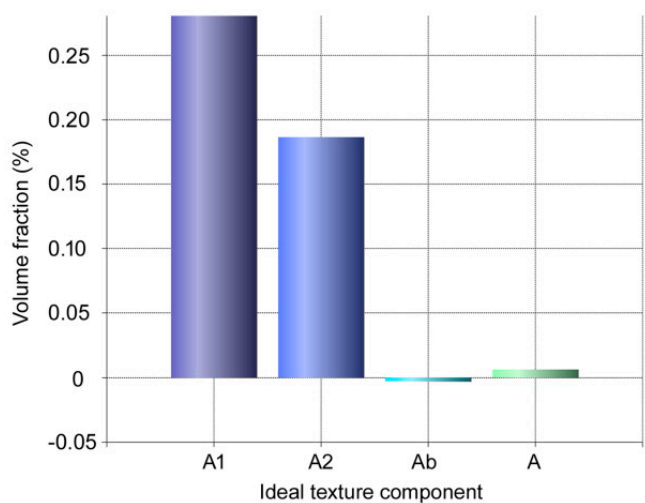

(a)

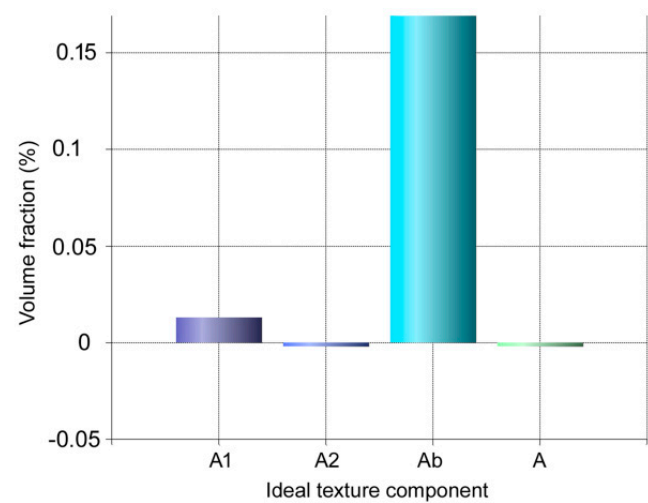

(b)

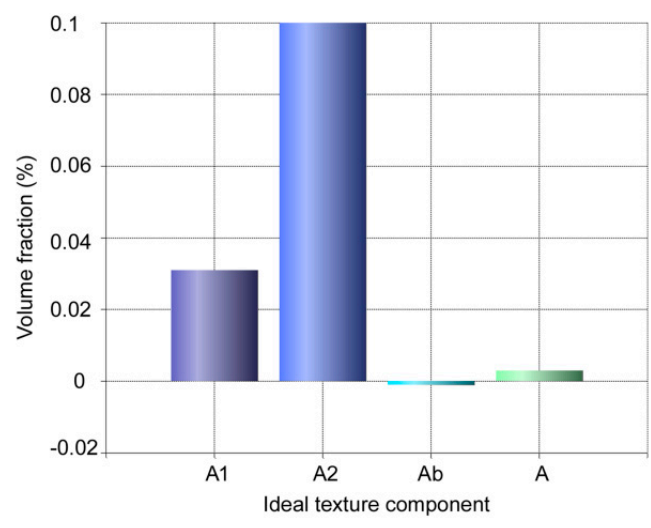

(c)

Figure 5. Cont. 


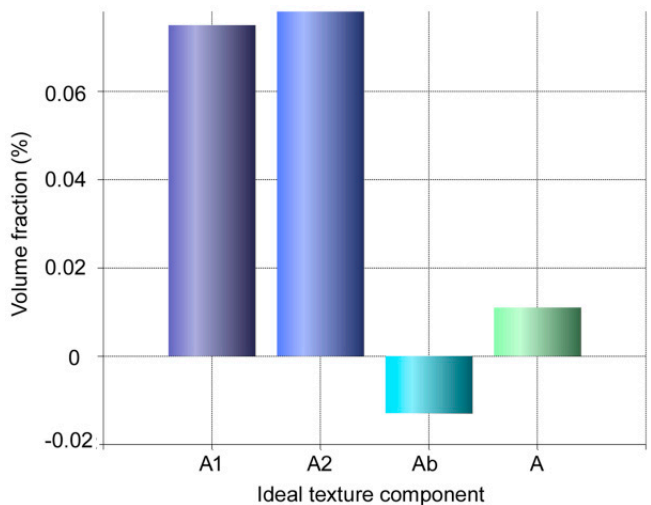

(d)

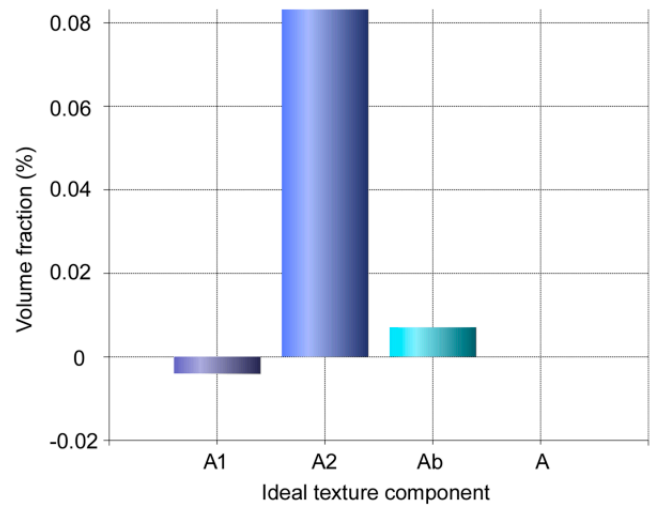

(e)

Figure 5. Volume fractions of dominant ideal texture orientations for individual wires within composite billet extruded via double pass TCAP: upper left (a); upper right (b); axial (c); bottom left (d); and bottom right (e).

\subsection{Microhardness and Structure of Extruded Composites}

The deformation strengthening introduced by the intensive shear strain and manifesting itself in macrodeformation and bending of the ends of the $\mathrm{Cu}$ wires (Section 3.1) contributed to increases in microhardness for both the experimentally extruded composite components. The original HV values of the initial annealed components were 58.6 for the $\mathrm{Cu}$ wires, and 37.4 for the $\mathrm{Al}$ sheath. Figure $6 \mathrm{a}, \mathrm{b}$ depicts the maps of microhardness measured across the cross-sections of both the extruded billets. As can be seen, the microhardness values increased after both the single and double pass TCAP. After single pass TCAP, the average microhardness value of the $\mathrm{Al}$ sheath increased to $85 \mathrm{HV}$, and for the $\mathrm{Cu}$ wires it increased up to $107 \mathrm{HV}$. After the second pass, the average value of the $\mathrm{Al}$ was comparable to the first pass $(86 \mathrm{HV})$, while for the $\mathrm{Cu}$ wires the average $\mathrm{HV}$ value increased to $128 \mathrm{HV}$.

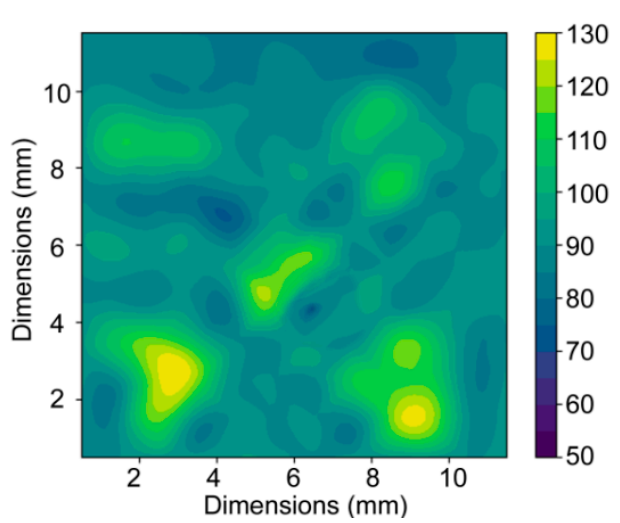

(a)

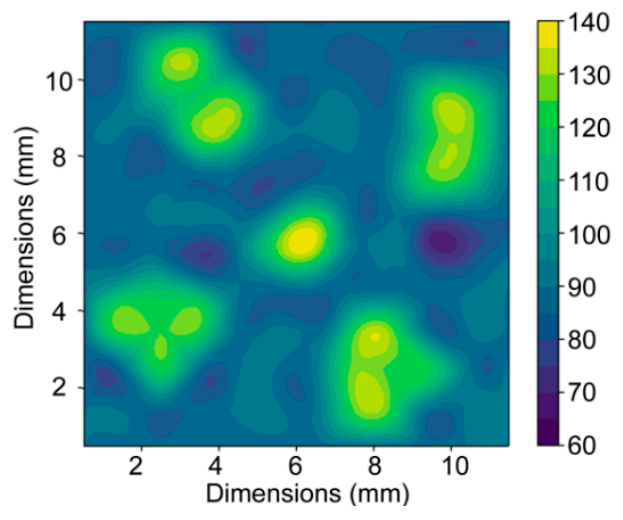

(b)

Figure 6. Maps of experimentally measured microhardness across a cross-section of billet after: single pass (a) and double pass (b).

The results point to the fact that the $\mathrm{Cu}$ was not strengthened to its limit after the single pass, i.e., its structure was not saturated [59], by the effect of which the microhardness still increased after the second pass. On the other hand, the Al sheath featured structure saturation already after the first pass, and then exhibited structure recovery/recrystallization at the expense of further strengthening after the second pass. This supposition is in accordance with the grain refinement of the Al sheath occurring after both the passes. After single TCAP pass, the average grain size within the Al sheath was $5.4 \mu \mathrm{m}$, which was comparable with the values acquired during the previous study on a $\mathrm{CP} A \mathrm{l}$ 
billet [50,51]. However, after the second pass, the average grain size within the Al sheath decreased down to $1.75 \mu \mathrm{m}$ (see the orientation image map-OIM-and grain size distribution in Figure 7a,b). For comparison, the OIMs for the axial wire within the billets extruded via the single and double TCAP pass are depicted in Figure 7c,d, respectively, clearly showing that the grain size of the Cu wires was larger than within the Al sheath.

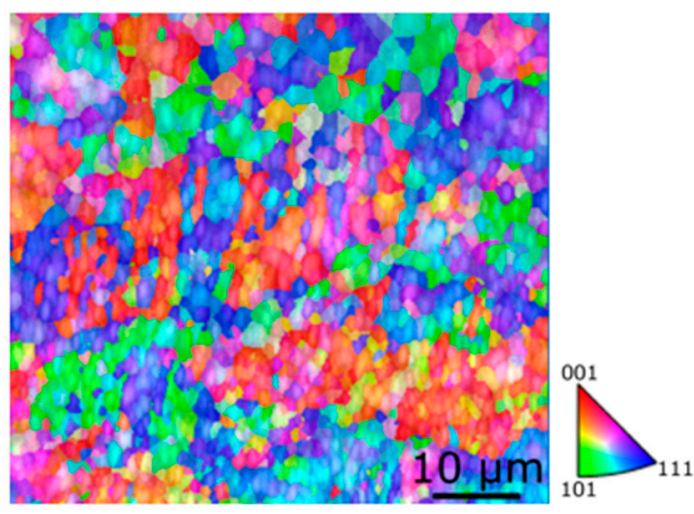

(a)

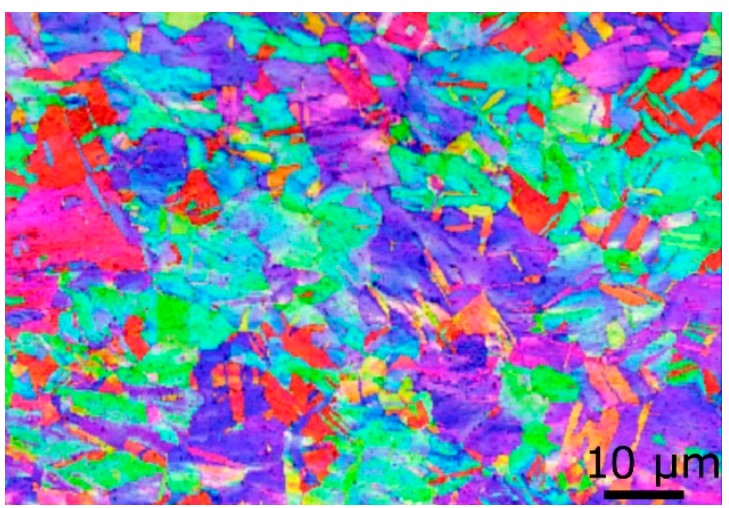

(c)

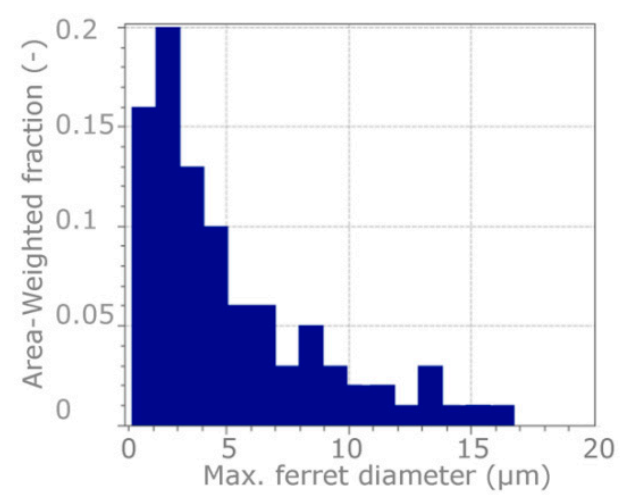

(b)

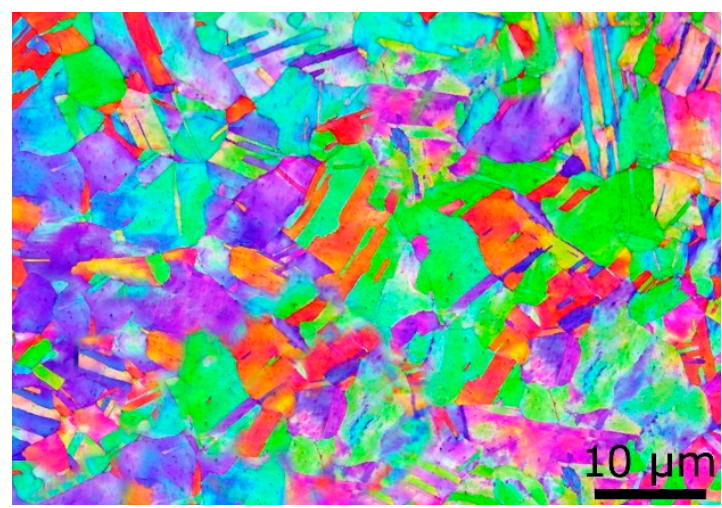

(d)

Figure 7. Structure of $\mathrm{Al}$ sheath after double pass TCAP: orientation image map (OIM) (a); grain size distribution (b); OIM of axial Cu wire after: Single TCAP (c); and double TCAP (d).

\section{Discussion}

Both the predicted and experimental results revealed that the deformation behavior of the composite billet was affected by the fact that it consisted of a combination of two different component metals. However, the individual deformation zones implemented within the die and the selected deformation route had non-negligible effects on the behavior of the billet, too. Passing through the TDZ did not generally introduce as high strains as passing through the MDZ [49]; the MDZ affects primarily the composite axial region, while the TDZ imposes high effective strain primarily to the composite (sub)surface regions. The TDZ thus imposed the shear strain primarily to the Al sheath, the plastic flow in the outer region of which was quicker than in the $\mathrm{Cu}$ wires. Subsequently, the MDZ contributed to the increase in the imposed shear strain also within the wires. The predicted bendings of the ends of the $\mathrm{Cu}$ wires after both the TCAP passes originating from different plastic flows of the individual regions of the composite billet developed during passing through the MDZ, where the upper cross-sectional region of the $\mathrm{Al}$ sheath adjoining to the $\mathrm{Cu}$ wires exhibited a tendency to flow quicker than the bottom cross-sectional region of the billet. 
The development of texture during TCAP was affected by the acting strain path along which the shear strain was imposed [50,51]. As described above, the TCAP die is characterized by two independent deformation zones, twist zone (analogy to twist extrusion) two independent intersection planes in which are active, and bending zone (analogy to ECAP) another intersection plane in which is active. The TCAP die thus introduces severe shear strain into the extruded composite along three independent intersection planes, which also introduces a high amount of lattice distortions acting as obstacles for the movement of dislocations, and generation of nucleation sites during substructure formation (both these occurring phenomena were confirmed via the observed microhardness increase, and substantial grain refinement, see Figures 6 and 7). After the first TCAP pass, the axial wire exhibited dominant A fiber texture orientation, which corresponds with the supposition of the minor effect of the TDZ on this wire during the first pass, since the A fiber is an ideal shear texture orientation developing during conventional ECAP. In other words, this finding documents the dominant effect of MDZ on this wire. The texture orientations identified in the peripheral wires were primarily affected by the two intersection planes along which the shear strain was imposed to the composite in the TDZ, especially as regards their tendency to mirror across the cross-sectional diagonals. Nevertheless, double pass TCAP resulted in homogenization of texture, as all the wires exhibited the tendencies to form A fiber dominant shear texture orientation.

\section{Conclusions}

The study presented the results of experimental analyses, supplemented with FEM numerical prediction, of an $\mathrm{Al} / \mathrm{Cu}$ clad composite prepared by room temperature extrusion via the twist channel angular pressing (TCAP) method (single and double pass). The numerical prediction showed that both the passes introduced severe shear strain to both the component metals; the maximum effective imposed strain within the $\mathrm{Al}$ sheath of the billet processed via the double pass reached to the value of 5. The severe imposed strain subsequently introduced significant grain refinement and deformation strengthening (especially after the second pass) resulting in the increase in microhardness up to $128 \mathrm{HV}$ for the $\mathrm{Cu}$ wires. The results also documented that the second pass introduced homogenization of the distribution of the imposed strain within the $\mathrm{Al}$ sheath and $\mathrm{Cu}$ wires, as well as uniform tendencies to form preferential texture orientations. The $\mathrm{Cu}$ wires exhibited the tendency to form A fiber preferential texture orientation after the second pass, although after the first pass, one pair of the peripheral wires exhibited the formation of A fiber texture, while the second pair formed C fiber texture.

Author Contributions: The contributions of the individual authors were the following: methodology, L.K. and Z.K.; numerical prediction and evaluation, Z.K.; experimental validation, L.K.; microscopy investigation and evaluation, L.K.; writing-original draft preparation, L.K.; writing-review and editing, L.K.; project administration, L.K.; funding acquisition, Z.K. All authors have read and agreed to the published version of the manuscript.

Funding: This research was supported by the FV40286 TRIO program by Ministry of Industry and Trade.

Acknowledgments: The authors would like to appreciate the kind cooperation of Michal Jambor, Adam Weiser, and the LaPAMat team of Institute of Physics of Materials, CAS, during preparation and evaluation of experimental material.

Conflicts of Interest: The authors declare no conflict of interest. The funders had no role in the design of the study; in the collection, analyses, or interpretation of data; in the writing of the manuscript, or in the decision to publish the results.

\section{References}

1. Matthews, F.L.; Rawlings, R.D. Composite Materials: Engineering and Science; CRC Press: Boca Raton, FL, USA, 1999.

2. Kocich, R.; Kunčická, L.; Král, P.; Strunz, P. Characterization of innovative rotary swaged Cu-Al clad composite wire conductors. Mater. Des. 2018, 160, 828-835. [CrossRef] 
3. Kunčická, L.; Kocich, R.; Dvořák, K.; Macháčková, A. Rotary swaged laminated Cu-Al composites: Effect of structure on residual stress and mechanical and electric properties. Mater. Sci. Eng. A 2019, 742, 743-750. [CrossRef]

4. Kunčická, L.; Kocich, R. Deformation behaviour of Cu-Al clad composites produced by rotary swaging. IOP Conf. Ser. Mater. Sci. Eng. 2018, 369, 012029. [CrossRef]

5. Clyne, T.W.; Withers, P.J. An Introduction to Metal Matrix Composites; Cambridge University Press: New York, NY, USA, 1993.

6. Tjong, S.; Ma, Z. Microstructural and mechanical characteristics of in situ metal matrix composites. Mater. Sci. Eng. R Rep. 2000, 29, 49-113. [CrossRef]

7. Viswanathan, V.; Laha, T.; Balani, K.; Agarwal, A.; Seal, S. Challenges and advances in nanocomposite processing techniques. Mater. Sci. Eng. R Rep. 2006, 54, 121-285. [CrossRef]

8. Moya, J.S.; Lopez-Esteban, S.; Pecharromán, C. The challenge of ceramic/metal microcomposites and nanocomposites. Prog. Mater. Sci. 2007, 52, 1017-1090. [CrossRef]

9. Meilakh, A.G.; Kontsevoi, Y.V.; Shubin, A.B.; Pastukhov, E.A. Steel composites based on copper-clad iron powder. Steel Transl. 2015, 45, 712-715. [CrossRef]

10. Wang, D.; Dong, X.; Zhou, P.; Sun, A.; Duan, B. The sintering behavior of ultra-fine Mo-Cu composite powders and the sintering properties of the composite compacts. Int. J. Refract. Met. Hard Mater. 2014, 42, 240-245. [CrossRef]

11. Rhee, K.Y.; Han, W.Y.; Park, H.J.; Kim, S.S. Fabrication of aluminum/copper clad composite using hot hydrostatic extrusion process and its material characteristics. Mater. Sci. Eng. A 2004, 384, 70-76. [CrossRef]

12. Kwon, H.C.; Jung, T.K.; Lim, S.C.; Kim, M.S. Fabrication of Copper Clad Aluminum Wire (CCAW) by Indirect Extrusion and Drawing. Mater. Sci. Forum 2004, 449-452, 317-320. [CrossRef]

13. Mehr, V.Y.; Toroghinejad, M.R.; Rezaeian, A. The effects of oxide film and annealing treatment on the bond strength of Al-Cu strips in cold roll bonding process. Mater. Des. 2014, 53, 174-181. [CrossRef]

14. Kunčická, L.; Kocich, R.; Strunz, P.; Macháčková, A. Texture and residual stress within rotary swaged Cu/Al clad composites. Mater. Lett. 2018, 230, 88-91. [CrossRef]

15. Sapanathan, T.; Khoddam, S.; Zahiri, S.H.; Zarei-Hanzaki, A. Strength changes and bonded interface investigations in a spiral extruded aluminum/copper composite. Mater. Des. 2014, 57, 306-314. [CrossRef]

16. Zebardast, M.; Taheri, A.K. The cold welding of copper to aluminum using equal channel angular extrusion (ECAE) process. J. Mater. Process. Technol. 2011, 211, 1034-1043. [CrossRef]

17. Lapovok, R.; Ng, H.P.; Tomus, D.; Estrin, Y. Bimetallic copper-aluminium tube by severe plastic deformation. Scr. Mater. 2012, 66, 1081-1084. [CrossRef]

18. Kocich, R.; Szurman, I.; Kursa, M.; Fiala, J. Investigation of influence of preparation and heat treatment on deformation behaviour of the alloy NiTi after ECAE. Mater. Sci. Eng. A 2009, 512, 100-104. [CrossRef]

19. Naizabekov, A.B.; Andreyachshenko, V.A.; Kocich, R. Study of deformation behavior, structure and mechanical properties of the AlSiMnFe alloy during ECAP-PBP. Micron 2013, 44, 210-217. [CrossRef]

20. Hlaváč, L.M.; Kocich, R.; Gembalová, L.; Jonšta, P.; Hlaváčová, I.M. AWJ cutting of copper processed by ECAP. Int. J. Adv. Manuf. Technol. 2016, 86, 885-894. [CrossRef]

21. Kunčická, L.; Kocich, R.; Drápala, J.; Andreyachshenko, V.A. FEM simulations and comparison of the ecap and ECAP-PBP influence on Ti6Al4V alloy's deformation behaviour. In Proceedings of the 22nd International Metallurgy and Materials Conference, Brno, Czech Republic, 15-17 May 2013; pp. 391-396.

22. Kunčická, L.; Kocich, R.; Ryukhtin, V.; Cullen, J.C.T.; Lavery, N.P. Study of structure of naturally aged aluminium after twist channel angular pressing. Mater. Charact. 2019, 152, 94-100. [CrossRef]

23. Kunčická, L.; Lowe, T.C.; Davis, C.F.; Kocich, R.; Pohludka, M. Synthesis of an $\mathrm{Al} / \mathrm{Al}_{2} \mathrm{O}_{3}$ composite by severe plastic deformation. Mater. Sci. Eng. A 2015, 646, 234-241. [CrossRef]

24. Kocich, R.; Macháčková, A.; Fojtík, F. Comparison of strain and stress conditions in conventional and ARB rolling processes. Int. J. Mech. Sci. 2012, 64, 54-61. [CrossRef]

25. Bachmaier, A.; Pippan, R. Generation of metallic nanocomposites by severe plastic deformation. Int. Mater. Rev. 2013, 58, 41-62. [CrossRef]

26. Huang, X.; Tsuji, N.; Hansen, N.; Minamino, Y. Microstructural evolution during accumulative roll-bonding of commercial purity aluminum. Mater. Sci. Eng. A 2003, 340, 265-271. [CrossRef]

27. Dinda, G.P.; Rösner, H.; Wilde, G. Synthesis of bulk nanostructured Ni, Ti and Zr by repeated cold-rolling. Scr. Mater. 2005, 52, 577-582. [CrossRef] 
28. Pippan, R.; Scheriau, S.; Taylor, A.; Hafok, M.; Hohenwarter, A.; Bachmaier, A. Saturation of Fragmentation during Severe Plastic Deformation. Annu. Rev. Mater. Res. 2010. [CrossRef]

29. Tolaminejad, B.; Taheri, A.K.; Shahmiri, M.; Arabi, H. Development of Crystallographic Texture and Grain Refinement in the Aluminum Layer of $\mathrm{Cu}-\mathrm{Al}-\mathrm{Cu}$ Tri-Layer Composite Deformed by Equal Channel Angular Extrusion. Int. J. Mod. Phys. Conf. Ser. 2012, 5, 325-334. [CrossRef]

30. Suehiro, K.; Nishimura, S.; Horita, Z.; Mitani, S.; Takanashi, K.; Fujimori, H. High-pressure torsion for production of magnetoresistance in Cu-Co alloy. J. Mater. Sci. 2008, 43, 7349-7353. [CrossRef]

31. Ohsaki, S.; Kato, S.; Tsuji, N.; Ohkubo, T.; Hono, K. Bulk mechanical alloying of Cu-Ag and Cu/Zr two-phase microstructures by accumulative roll-bonding process. Acta Mater. 2007, 55, 2885-2895. [CrossRef]

32. Wilde, G.; Rösner, H. Stability aspects of bulk nanostructured metals and composites. J. Mater. Sci. 2007, 42, 1772-1781. [CrossRef]

33. Sabirov, I.; Schöberl, T.; Pippan, R. Fabrication of a W-25\%Cu Nanocomposite by high pressure torsion. Mater. Sci. Forum 2006, 503-504, 561-566. [CrossRef]

34. Kim, W.N.; Hong, S.I. Interactive deformation and enhanced ductility of tri-layered $\mathrm{Cu} / \mathrm{Al} / \mathrm{Cu}$ clad composite. Mater. Sci. Eng. A 2016, 651, 976-986. [CrossRef]

35. Movahedi, M.; Kokabi, A.H.; Reihani, S.M.S. Investigation on the bond strength of Al-1100/St-12 roll bonded sheets, optimization and characterization. Mater. Des. 2011, 32, 3143-3149. [CrossRef]

36. Hosseini, M.; Manesh, H.D. Bond strength optimization of Ti/Cu/Ti clad composites produced by roll-bonding. Mater. Des. 2015, 81, 122-132. [CrossRef]

37. Polyanskii, S.N.; Kolnogorov, V.S. Cladded steel for the oil and gas industries. Chem. Pet. Eng. 2002, 38, 703-707. [CrossRef]

38. Li, X.; Zu, G.; Ding, M.; Mu, Y.; Wang, P. Interfacial microstructure and mechanical properties of $\mathrm{Cu} / \mathrm{Al}$ clad sheet fabricated by asymmetrical roll bonding and annealing. Mater. Sci. Eng. A 2011, 529, 485-491. [CrossRef]

39. Li, X.; Zu, G.; Wang, P. Effect of strain rate on tensile performance of $\mathrm{Al} / \mathrm{Cu} / \mathrm{Al}$ laminated composites produced by asymmetrical roll bonding. Mater. Sci. Eng. A 2013, 575, 61-64. [CrossRef]

40. Matli, P.R.; Fareeha, U.; Shakoor, R.A.; Mohamed, A.M.A. A comparative study of structural and mechanical properties of $\mathrm{Al}-\mathrm{Cu}$ composites prepared by vacuum and microwave sintering techniques. J. Mater. Res. Technol. 2018, 7, 165-172. [CrossRef]

41. Matvienko, Y.I.; Polishchuk, S.S.; Rud, A.D.; Popov, O.Y.; Demchenkov, S.A.; Fesenko, O.M. Effect of graphite additives on microstructure and mechanical properties of Al-Cu composites prepared by mechanical alloying and sintering. Mater. Chem. Phys. 2020, 254, 123437. [CrossRef]

42. Zhang, J.; Wang, B.; Chen, G.; Wang, R.; Miao, C.; Zheng, Z.; Tang, W. Formation and growth of Cu-Al IMCs and their effect on electrical property of electroplated $\mathrm{Cu} / \mathrm{Al}$ laminar composites. Trans. Nonferrous Met. Soc. Chin. 2016, 26, 3283-3291. [CrossRef]

43. Bouaziz, O.; Bréchet, Y.; Embury, J.D. Heterogeneous and architectured materials: A possible strategy for design of structural materials. Adv. Eng. Mater. 2008, 10, 24-36. [CrossRef]

44. Martinsen, K.; Hu, S.J.; Carlson, B.E. Joining of dissimilar materials. CIRP Ann. 2015, 64, 679-699. [CrossRef]

45. Bouaziz, O.; Kim, H.S.; Estrin, Y. Architecturing of metal-based composites with concurrent nanostructuring: A new paradigm of materials design. Adv. Eng. Mater. 2013, 15, 336-340. [CrossRef]

46. Khoddam, S.; Estrin, Y.; Kim, H.S.; Bouaziz, O. Torsional and compressive behaviours of a hybrid material: Spiral fibre reinforced metal matrix composite. Mater. Des. 2015, 85, 404-411. [CrossRef]

47. Khoddam, S.; Sapanathan, T.; Zahiri, S.; Hodgson, P.D.; Zarei-Hanzaki, A.; Ibrahim, R. Inner architecture of bonded splats under combined high pressure and shear. Adv. Eng. Mater. 2016, 18, 501-505. [CrossRef]

48. Kocich, R.; Greger, M.; Kursa, M.; Szurman, I.; Macháčková, A. Twist channel angular pressing (TCAP) as a method for increasing the efficiency of SPD. Mater. Sci. Eng. A 2010, 527, 6386-6392. [CrossRef]

49. Kocich, R.; Kunčická, L.; Mihola, M.; Skotnicová, K. Numerical and experimental analysis of twist channel angular pressing (TCAP) as a SPD process. Mater. Sci. Eng. A 2013, 563, 86-94. [CrossRef]

50. Kocich, R.; Kunčická, L.; Král, P.; Macháčková, A. Sub-structure and mechanical properties of twist channel angular pressed aluminium. Mater. Charact. 2016, 119, 75-83. [CrossRef]

51. Kunčická, L.; Kocich, R.; Král, P.; Pohludka, M.; Marek, M. Effect of strain path on severely deformed aluminium. Mater. Lett. 2016, 180, 280-283. [CrossRef] 
52. Kocich, R.; Fiala, J.; Szurman, I.; Macháčková, A.; Mihola, M. Twist-channel angular pressing: Effect of the strain path on grain refinement and mechanical properties of copper. J. Mater. Sci. 2011, 46, 7865-7876. [CrossRef]

53. Macháčková, A. Decade of twist channel angular pressing: A review. Materials 2020, 13, 1725. [CrossRef]

54. Beausir, B.; Fundenberger, J.J. Analysis Tools for Electron and X-ray Diffraction. ATEX-Software. 2017. Available online: www.atex-software.eu (accessed on 20 July 2020).

55. Kocich, R.; Greger, M.; Macháčková, A. Finite element investigation of influence of selected factors on ECAP process. In Proceedings of the METAL 2010-19th International Conference on Metallurgy and Materials, Roznov pod Radhostem, Czech Republic, 18-20 May 2010; Tanger Ltd.: Ostrava, Czech Republic, 2010; pp. 166-171.

56. Beyerlein, I.J.; Tóth, L.S. Texture evolution in equal-channel angular extrusion. Prog. Mater. Sci. 2009, 54, 427-510. [CrossRef]

57. Li, S.; Beyerlein, I.J.; Alexander, D.J.; Vogel, S.C. Texture evolution during multi-pass equal channel angular extrusion of copper: Neutron diffraction characterization and polycrystal modeling. Acta Mater. 2005, 53, 2111-2125. [CrossRef]

58. Engler, O.; Randle, V. Introduction to Texture Analysis, Macrotexture, Microtexture, and Orientation Mapping, 2nd ed.; Taylor and Francis Group: Milton, UK, 2010.

59. Russell, A.; Lee, K.L. Structure-Property Relations in Nonferrous Metals, 1st ed.; John Wiley \& Sons, Inc.: Hoboken, NJ, USA, 2005.

(C) 2020 by the authors. Licensee MDPI, Basel, Switzerland. This article is an open access article distributed under the terms and conditions of the Creative Commons Attribution (CC BY) license (http://creativecommons.org/licenses/by/4.0/). 